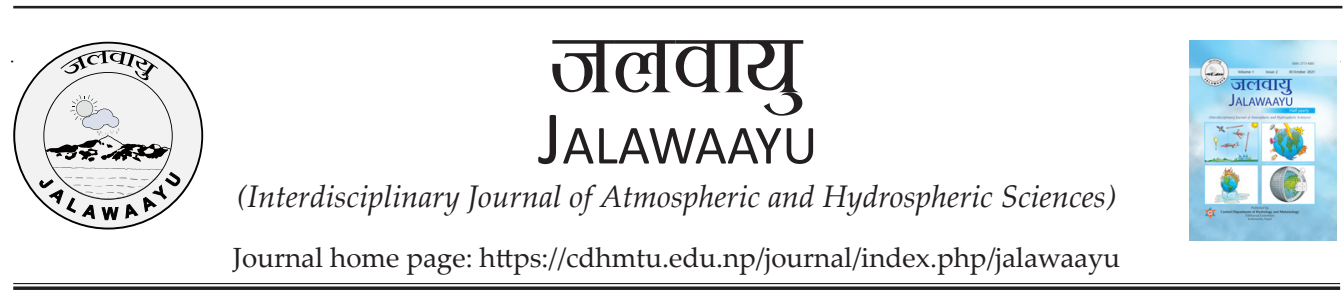

Research Article

\title{
Spatial Pattern of Precipitation in GPM-Era Satellite Products against Rain Gauge Measurements over Nepal
}

\author{
Bharat Badayar Joshi ${ }^{1,2}$, Munawar Ali ${ }^{1}$, Dibit Aryal ${ }^{1}$, Laxman Paneru ${ }^{3}$, and Bhaskar \\ Shrestha $\mathbf{a}^{4,5}$ * \\ 1 Institute of Tibetan Plateau Research, Beijing 100049, China \\ 2 Kathmandu Center for Research and Education, CAS-TU, Kirtipur, Nepal \\ 3 Central Department of Hydrology and Meteorology, Tribhuvan University, Kirtipur, Nepal \\ 4 University of Chinese Academy of Sciences, Beijing 100049, China \\ 5 State Key Laboratory of Remote Sensing Science, Aerospace Information Research Institute, Chinese \\ Academy of Sciences, Beijing 100049, China
}

\begin{tabular}{l}
\hline ARTICLE INFO \\
\hline Received: 20 March 2021 \\
Received in Revised form: 31 May 2021 \\
Accepted: 3 June 2021 \\
Available Online: 2 December 2021 \\
\hline Keywords \\
\hline Satellite Precipation \\
IMERG \\
GSMaP \\
Nepal \\
Mountains \\
\hline${ }^{*}$ Correspondence \\
\hline Bhaskar Shrestha \\
bhas.stha70@mails.ucas.ac.cn
\end{tabular}

Abstract: Precipitation in a mountainous region is highly variable due to the complex terrain. Satellite-based precipitation estimates are potential alternatives to gauge measurements in these regions, as these typical measurements are not available or are scarce in high elevation areas. However, the accuracy of these gridded precipitation datasets need to be addressed before further usage. In this study, an evaluation of the spatial precipitation pattern in satellite-based precipitation products is provided, including satellite-only (Integrated Multisatellite Retrievals for GPM IMERG-UCORR and Global Satellite Mapping of Precipitation (GSMaP-MVK) and gauge calibrated (IMERG-CORR and GSMaP-Gauge) products, with a spatial resolution of $0.1^{\circ}$, which is compared to 387-gauge measurements in Nepal from April 2014 to December 2016. The major results are as follows: (1) The 
gauge calibrated version 5 IMERG-CORR and version 6 GSMaP-Gauge are relatively better than the satellite-only datasets, although they all underestimate the observed precipitation. (2) The daily gauge calibrated GSMaP-Gauge performs fairly well in low and mid-elevation areas, whereas the monthly gauge calibrated IMERG-C performs better in high-elevation areas. (3) For the daily time scale, IMERG-CORR shows a better ability to detect the true precipitation (higher Probability of Detection (POD)) and (lowest False Alarm Ratio (FAR)) events among all datasets. However, all four satellite-based precipitation datasets accurately detect (Critical Success Index (CSI) $>40 \%$ ) precipitation and no-precipitation events. The results of this work provide the systematic quantification of IMERG and GSMaP of satellite precipitation products over Nepal using station observations and delivers a helpful statistical basis for the selection of these datasets for future scientific research.

\section{Introduction}

Precipitation is a fundamental component of the water cycle. Understanding is paramount for managing water systems under a changing climate (Daly et al., 2017; Schneider et al., 2016; Aryal et al., 2020). Mountainous regions play a significant role in regional water resource conservation and sustainable use (Viviroli and Weingartner, 2004). However, these important regions are vulnerable to climate change and several hydro-meteorological hazards, such as floods and landslides. Moreover, the quality and availability of precipitation estimates have a consequential effect on the precision and reliability of meteorological, hydrological, and natural calamities studies (Viviroli et al., 2007; Viviroli et al., 2011).

Nepal is a mountainous country, covering almost $85 \%$ of the area by hills and mountains, making the country prone to slope failure causing landslides and debris flows. The Himalayas are water towers and the primary source of many rivers supporting millions of people downstream (Hannah et al., 2005; Sharma et al., 2005; Immerzeel et al., 2020). Precipitation in Nepal is predominantly governed by the summer monsoon system and is highly variable due to complex topography (Krakauer et al., 2013; Hamal et al., 2020a; Hamal et al., 2021). Rain Gauge-based stations provide relatively accurate and actual precipitation measurements at discrete locations on the ground surface (Sun et al., 2018; Hamal et al., 2020c; Sharma et al., 2020c; Sharma et al., 2021b). However, these stations are inadequate for hydro-meteorological studies as their distribution is sporadic. The stations are denser in low lands than high elevation areas (Diodato et al., 2010), leaving the latter underreported estimating precipitation records. Furthermore, the paucity of rain gauge observation hampers comprehensive water management, water resources studies, and the country's discernment of precipitation patterns (Islam et al., 2010). However, high-resolution satellite-based precipitation (SBP) products are the potential alternatives for monitoring precipitation on regular grids nearby. They represent unprecedented measurements over remote areas, especially in a mountainous region where stations are very sparse. However, these estimates are indirect measurements and must be calibrated or verified using gauge observations before further applications (Tian and Peters-Lidard, 2010).

Satellite precipitation estimates are based on one or more remotely-sensed characteristics of clouds, such as reflectivity (Visible), cloud-top temperature (IR 
imagery), or from the scattering effect of raindrops particles (i.e., Passive Microwave (PMW) radiation (Hou et al., 2014; Seto et al., 2013; Kidd and Huffman, 2011). Global Precipitation Measurement Core Observation network (GPM-CO) carries a DualFrequency Precipitation Radar (DPR) and a multi-channel GPM Microwave Imager (GMI), which has better precipitation measuring capabilities than previous TRMM instruments (Hou et al., 2014). After the success of the Tropical Rainfall Measuring Mission (TRMM), the National Aeronautics and Space Administration (NASA) and the Japanese Aerospace Exploration Agency (JAXA) launched the GPM-CO in February 2014. Two new SBP were introduced after the GPM mission was launched: the Integrated Multi-Satellite Retrievals for GPM (IMERG) and Global Satellite Mapping Precipitation (GSMaP) product of $0.1^{\circ}$ spatial resolution, with half-hourly and hourly temporal scales, respectively (Satge et al., 2017). GPM-IMERG takes advantage of several existing precipitation retrieval algorithms, including TRMM Multi-satellite Precipitation Analysis (TMPA), Climate Prediction Center Morphing with Kalman Filter (CMORPHKF), and Precipitation Estimation from Remotely Sensed Information using Artificial Neural Networks and a Cloud Classification System (PERSIANN-CCS) (Huffman et al., 2017). Meanwhile, GSMaP uses its precipitation retrieving algorithm by assimilating PMW information from GPM Core GMI. PMW based precipitation estimates are more reliable as the observations are analogous to hydrometeorology content present within the atmospheric column (Derin et al., 2016; Huffman et al., 2010; Huffman et al., 2015a). The accuracy of these satellite-based remote sensing precipitation products remains uncertain and poorly investigated, especially in mountainous regions.

Several studies have previously applied SBP products around the globe (Krakauer et al., 2013; Satge et al., 2018; Shen and Xiong, 2016; Tan et al., 2017; Viviroli et al., 2007; Yamamoto et al., 2011; Brown, 2006), and confirmed that newer versions (i.e. V6) of IMERG precipitation datasets are better than its earlier version and previous generation TRMM (Chen and Li, 2016; Prakash et al., 2018; Tang et al., 2016). Further, few studies have been conducted in Nepal using the newer version SBP, whereas critical evaluation of the previous version of SBP (GSMaP, GPM-IMERG) and inter-comparison between these products have not been performed yet. For example, (Bhatt and Nakamura, 2005; Bookhagen and Burbank, 2006) used TRMM precipitation to study precipitation seasonality and diurnal variations over the Himalayas; however, they did not validate the SBP against observations. Yatagai and Kawamoto (2008) found TRMM Precipitation Radar (PR) product underestimated precipitation over the Khumbu area (Himalayan region) of the country. Similarly, (Islam et al., 2010) also found TRMM precipitation product underestimated the observed precipitation; however, they have used only 15 stations for observation data from Nepal without considering geographical variation in the calibration factor. In contrast, (Duncan and Biggs, 2012) indicated that TRMM generally overestimated gauge-based gridded precipitation product (APHRODITE) over Nepal. Studies on spatial comparison with gauge observation found that GSMaP severely underestimated the observed precipitation by about $48 \%$ (Shrestha, 2011).

Moreover, the TRMM 3B-43 precipitation product exhibits reasonable skill in computing precipitation over mountainous Nepal (Krakauer et al., 2013). They also mention that TRMM product shows potentiality for application in water resources management while GSMaP, CMORPH, and PERSIANN were incompetent in 
reproducing station precipitation amounts. Recently, (Nepal et al., 2021; Sharma et al., 2020a; Sharma et al., 2020d) have used the latest version (version 6) of GPM-era satellite product for their accuracy. Overall, errors in satellite-based precipitation estimates are partly related to complex topography, underlying surface types, and sensor capability. However, the most recognized and widely used previous versions of satellite products to present the spatial pattern are not analyzed over Nepal. Therefore, this study evaluated the version 5 IMERG (IMERG-CORR, and IMERG-UNCOR) and version 6 GSMaP (GSMaP-MVK, GSMaP-gauge) products for their accuracy and studying the spatial pattern of precipitation over Nepal. The evaluated datasets include both gaugecalibrated and un-calibrated GPM-IMERG and GSMaP products.

\section{Materials and Methods}

\subsection{Study Area}

Nepal is a South Asian country located approximately between $26.36^{\circ}-30.45^{\circ} \mathrm{N}$ latitude and $80.06^{\circ}-88.2^{\circ} \mathrm{E}$ longitude (Figure 1). It encompasses the northern part of the Indo-Gangetic plains and the southern part of the high Himalayan range covering $147,516 \mathrm{~km}^{2}$. About $85 \%$ of the country is comprised of hilly and mountainous regions, with the remaining $14 \%$ as flatland (Chen et al., 2021). Its topography varies from almost $60 \mathrm{~m}$ in the southern lowland to the world's highest peak, i.e., Mt. Everest, at an altitude of $8848.86 \mathrm{~m}$ above sea level, in the north within a short distance of $\sim 150-200 \mathrm{~km}$. The geography of the country is broadly divided into Lowlands (Terai and Siwaliks), Hills (Middle and High Mountains), and High Himalayas (Duncan and Biggs, 2012). The country's climate is very diverse in space and seasons, which is governed by south Asian summer monsoons and a westerly wind system. Pre-monsoon (March-May), summer monsoon (June-September), post-monsoon (October-November), and winter seasons (December-February) are the primary climatological seasons (Nayava, 1980). Among these seasons, post-monsoon and winter seasons are generally dry. In contrast, the pre-monsoon and monsoon seasons are wet and humid (Shrestha, 2000; Sharma et al., 2021a). Low-land and Mid-Mountains receive large amounts of precipitation during the summer monsoon from July to September as part of the South Asian monsoon, which is the country's primary source of annual precipitation (Hamal et al., 2020a; Hamal et al., 2020b; Hamal et al., 2020c; Sharma et al., 2020b; Shrestha and Deshar, 2014; Shrestha et al., 2021). Meanwhile, the northern part of the high Himalayas, including trans-Himalayan regions, is relatively dry as mountains block the precipitation and are known as rain shadow areas (Dawadi et al., 2020; Pokharel et al., 2019; Talchabhadel and Karki, 2019; Talchabhadel et al., 2018). 


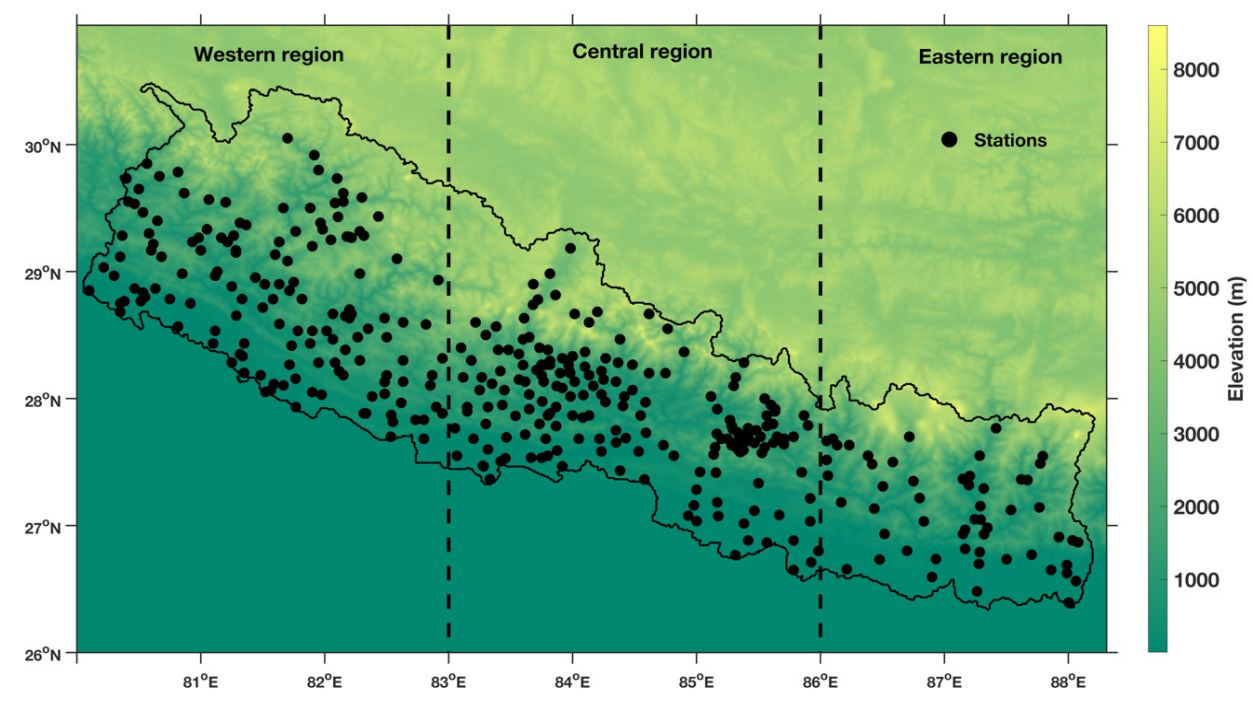

Figure 1. Study area Nepal and distribution of 387 meteorological stations.

\subsection{Ground Data}

This study used daily rainfall data of 387 stations across Nepal from April 2014 to 2016 (Figure 1). This data was collected from the Department of Hydrology and Meteorology (DHM), the Government of Nepal that owns the hydro-meteorological station and is responsible for data collection. The distribution of these rain gauge stations is very erratic. Most of the stations are located in mid, and low-altitude regions, and existing stations in higher altitudes are inadequate to represent the precipitation variability of the country. Most of these stations are manual-type, therefore subject to personnel and instrumental errors. The mean annual precipitation of selected individual rain gauge stations during the study period is presented in Figure 2a.

\subsection{Satellite datasets}

IMERG is the global multi-satellite precipitation product developed by National Aeronautic Space Agency (NASA). It combines the infrared (IR) satellite estimates, microwave (MW) precipitation estimates and is finally adjusted by monthly gauge observation from the Global Precipitation Climatology Centre (GPCC) (Huffman et al., 2015b; Huffman et al., 2017). The IMERG system runs three times, Early, Late, and Final Run. The Early Run product provides a preliminary estimate after 4hrs of the observation time, while the Late Run product is available after $12 \mathrm{hrs}$ of observation time. The Final Run product combines Late Run and gauges observation, which is available after 2.5 months of observation time (Huffman et al., 2017). Among these three IMERG products, Final Run is mainly recommended for Research purposes (Tan et al., 2017; Huffman et al., 2015b). There are two precipitation data field variables embedded in the Final Run product: monthly GPCC gauge calibrated multi-satellite precipitation 
estimated as a "precipitationCal" (hereafter IMERG-CORR) and the original multisatellite precipitation estimate "precipitationUncal" (hereafter IMERG-UNCOR). For this study, Half hourly Final Run version 5B IMERG-UNCOR and IMERG-CORR with spatial resolution of $10 \mathrm{~km}$ from April 2014 to December 2016 were acquired from the PMW website (https://gpm.nasa.gov/data-access/downloads/gpm).

GSMaP is a satellite-based precipitation product of the Japan Science and Technology (JST) agency under the Core Research for Evolutional Science and Technology (CREST) (Satge et al., 2018). GSMaP combines various available PMW and IR sensors (Shige et al., 2009). While developing GSMaP precipitation product, the instantaneous precipitation rate is retrieved based on the PMW radiometers from different satellite platforms, including GMI, advanced microwave scanning radiometer 2 (AMSR2), TRMM Microwave Imager (TMI), special sensor microwave imager/ sounder (SSMIS), advanced microwave sounding unit-A (AMSU-A), and microwave humidity sounder (MHS). Subsequently, the gaps between PMW-based estimates are propagated using the cloud motion vectors computed from geo-IR images, and a Kalman filter approach is applied to refine the precipitation rate (Ushio et al., 2009). Finally, forward, and backward propagated precipitation estimates are weighted and combined to generate the GSMaP-MVK product (Hou et al., 2014).

GSMaP-MVK also uses IR to correct satellite estimates but adopts various PWM imagers and sounders; it has a latency of 3 days. In addition to PWM and IR, GSMaPGauge is a gauge-calibrated product that adjusts the GSMaP-MVK estimate with National Oceanic and Atmospheric Administration (NOAA)/Climate Prediction Center (CPC) gauge-based analysis of global daily precipitation biases with a latency of 3 days. In the current study, version 6 GSMaP-MVK and GSMaP-Gauge (V06) were used. Mean annual precipitation during the study period of all SBPs is presented in Figure 2. An overview of the details of datasets is provided in Table 1.

Table 1. Overview of datasets included in this study with the corresponding spatial resolution, temporal coverage.

\begin{tabular}{|l|c|c|c|c|c|}
\hline \multicolumn{1}{|c|}{ Product } & $\begin{array}{c}\text { Temporal } \\
\text { Resolution }\end{array}$ & $\begin{array}{c}\text { Spatial } \\
\text { Resolution }\end{array}$ & Period & Coverage & References \\
\hline $\begin{array}{l}\text { DHM (gauge } \\
\text { observation) }\end{array}$ & 1 day & 387 stations & $2014.04-2016.12$ & Within Nepal & www.dhm.gov.np \\
\hline IMERG-UNCOR & $0.5 \mathrm{~h}$ & $0.1^{\circ}$ & $2014.04-2016.12$ & $90^{\circ} \mathrm{N}-90^{\circ} \mathrm{S}$ & \multirow{2}{*}{ (Huffman et al., 2019). } \\
\hline IMERG-CORR & $0.5 \mathrm{~h}$ & $0.1^{\mathrm{o}}$ & $2014.04-2016.12$ & $90^{\circ} \mathrm{N}-90^{\circ} \mathrm{S}$ & \\
\cline { 1 - 5 } GSMaP-MVK & $1 \mathrm{~h}$ & $0.1^{\mathrm{o}}$ & $2014.04-2016.12$ & $60^{\circ} \mathrm{N}-60^{\circ} \mathrm{S}$ & \multirow{2}{*}{ (Satge et al., 2018) } \\
\hline GSMaP-Gauge & $1 \mathrm{~h}$ & $0.1^{\mathrm{o}}$ & $2014.04-2016.12$ & $60^{\circ} \mathrm{N}-60^{\circ} \mathrm{S}$ & \multirow{2}{*}{} \\
\hline
\end{tabular}

\subsection{Methodology}

All SBPs precipitation products were extracted using the location of the observed gauge station (point-pixel method). Daily temporal datasets are computed using sub-daily SBP to match the time window of daily gauges observations for each station. Some of the gauge observation contains a missing value; thus, quality control is applied for data consistency. Accordingly, if the station featured more than $80 \%$ daily data in a month, it is averaged for monthly value; otherwise, precipitation is considered 
a missing value. To make consistent datasets, if there is a missing value in observation, SBP datasets were also considered missing values.

For each station, annual precipitation values of SBP and observation were generated by averaging monthly precipitation. To quantify spatial pattern in SBP, stations were divided into three different elevation sections, i.e., low-elevation (all stations below $1500 \mathrm{~m}$ ), mid-elevation (station located between 1500 and $2500 \mathrm{~m}$ ), and high-elevation (stations situated above $2500 \mathrm{~m}$ ) regions. Further, precipitation values were averaged at each station to quantify the performance of SBPs. Furthermore, precipitation detection capability of each SBP were calculated at each station along with the observation.

\subsubsection{Statistical analysis}

Following the previous studies (Hamal et al., 2020c; Sharma et al., 2020a; Shrestha et al., 2021), four different statistical metrics are adopted to analyze the performance of four SBP products: correlation coefficient (CC, Equation 1), Normalized Root Mean Square Error (NRMSE, Equation 2), mean biases (MB, Equation 3), and absolute relative error (RE, Equation 4). CC measures the strength and direction of the linear association between SBP and observation, while NRMSE provides the averaged magnitude of the deviation of SBP from observation. Furthermore, MB and RE show the average bias (underestimation or overestimation) and the difference between the magnitude of the SBP with observation, respectively.

$$
\begin{aligned}
& C C=\frac{\sum_{i=1}^{n}\left(G_{i}-G\right)\left(S_{i}-\bar{S}\right)}{\sqrt{\sum_{i=1}^{n}\left(G_{i}-\bar{G}\right)^{2}} \sqrt{\sum_{i=1}^{n}\left(S_{i}-\bar{S}\right)^{2}}} \\
& \text { NRMSE }=\frac{\sqrt{\frac{\sum_{i=1}^{n}\left(S_{i}-G_{i}\right)^{2}}{n}}}{\bar{G}} \\
& M B=\frac{(\bar{S}-\bar{G})}{n} \\
& \text { RE }=\left|\frac{M B}{\bar{G}}\right|
\end{aligned}
$$

${ }^{*}$ Where $\mathrm{G}$ is gauge observation, $\mathrm{S}$ is the SBPs, and n denotes the sample size.

Additionally, three skill indices are calculated at each station based on a $2 \times 2$ contingency table (Table 2) of daily rain/no-rain events. Since most DHM observations are collected manually, the threshold value for rain events is considered $1 \mathrm{~mm} / \mathrm{day}$. In Table 2, Q1 represents correctly estimated rain events of observation by SBP, Q2 and Q3 represent a false estimation of rain and no-rain event by SBP when there is no-rain and rain event in gauge observed data, respectively. Q4 refers to correctly estimated no-rain events by SBP. Skill indices - Probability of Detection (POD), also known as hit-rate, measures the fraction of the correctly diagnosed gauge observed events. False Alarm Ratio (FAR) gives the fraction of diagnosed events that did not occur, and Critical 
Success Index (CSI) measures how well SBP corresponds to gauge observed data that were corrected. The formula of statistical matrices is as follows.

$$
\begin{aligned}
& P O D=\frac{Q 1}{(Q 1+Q 3)} \\
& F A R=\frac{Q 2}{(Q 1+Q 2)} \\
& C S I=\frac{Q 1}{Q 1+Q 2+Q 3}
\end{aligned}
$$

Where Q1, Q2, Q3, and Q4 are the possible events shown in Table 2.

Table 2. Contingency Table to define daily precipitation based categorical scores for the evaluation of SBP with gauge observation.

\begin{tabular}{|c|c|c|c|}
\hline \multicolumn{4}{|c|}{ Gauges } \\
\hline \multirow{3}{*}{ SBP } & \multirow{2}{*}{$\begin{array}{c}\text { Precipitation } \\
\text { No Precipitation }\end{array}$} & Precipitation & No Precipitation \\
\cline { 3 - 4 } & & $\mathrm{Q} 1$ & Q2 \\
\cline { 3 - 4 } & & $\mathrm{Q} 3$ & Q4 \\
\hline
\end{tabular}

\section{Results}

\subsection{Spatial performance}

Figure 2(a through e) shows the spatial distribution of the mean annual precipitation ( $\mathrm{mm} /$ day) derived from the observed data and four different SBP datasets averaged for the study period. Comparing the spatial distributions of the observed precipitation, all four SBP datasets captured general spatial patterns, i.e., the highest amount of precipitation in the central Nepal. However, they differ largely in the precipitation amount and location accuracy. The observed maximum precipitation is more than $10 \mathrm{~mm} /$ day and centred at approximately $28.3^{\circ} \mathrm{N}, 84^{\circ} \mathrm{E}$ (Figure 2a). The annual precipitation distribution from GSMaP-Gauge (Figure 2e) shows similar characteristics with the maximum precipitation (approximately $8-10 \mathrm{~mm} /$ day) at $28.3^{0}$ $\mathrm{N}, 84^{\circ} \mathrm{E}$, whereas GSMaP-MVK shows the maximum precipitation (approximately 3-4 $\mathrm{mm}$ /day) at $28.5^{\circ} \mathrm{N}, 84^{\circ} \mathrm{E}$ (Figure $2 \mathrm{~b}$ ). In contrast, the IMERG-UNCORR and IMERGCORR datasets show the maximum precipitation (approximately $6-8 \mathrm{~mm} /$ day) at $27.8^{0}$ N, $84.7^{\circ}$ E (Figures $2 a$ and c). Overall, all four SBP datasets tend to underestimate the annual precipitation across the country. The estimated spatial pattern by GSMaP-Gauge (Figure 2e) is close to the observed dataset followed by IMERG-UNCOR (Figure 2b), and then IMERG-CORR (Figure 2d), whereas GSMaP-MVK (Figure 2c) shows the most dissimilarity with the observation. 

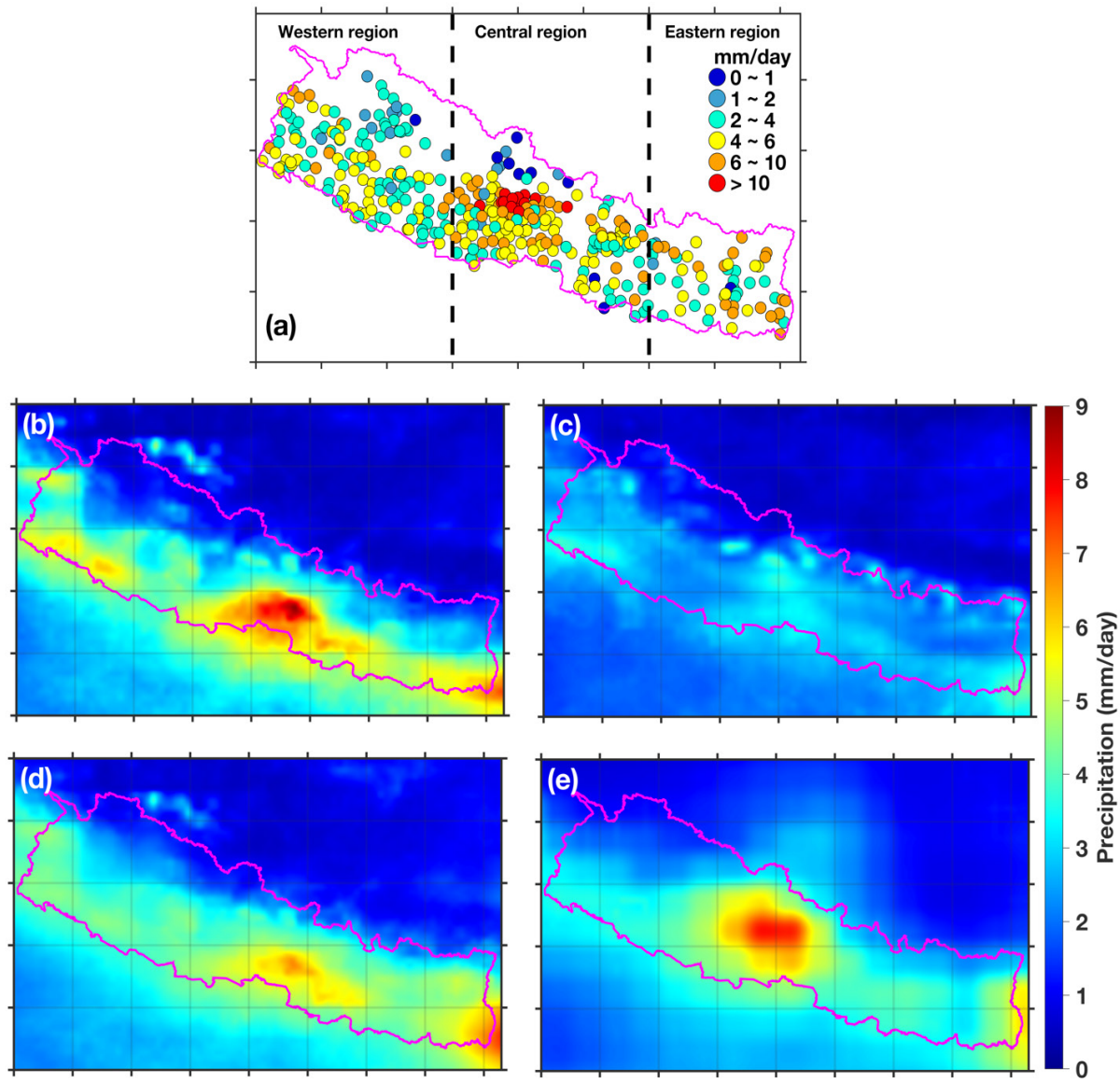

Figure 2. Spatial patterns of daily average precipitation (mm/day) in (a) observation, (b) IMERG-UNCOR, (c) GSMaP-MVK, (d) IMERG-CORR, and (e) GSMaP-Gauge from April 2014 to 2016.

To quantify the performances of SBPs at different elevation sections, we have compared all four SBP at three different elevations sections. Table 3 shows the statistical metrics derived from mean monthly precipitation averaged over below $1500 \mathrm{~m}$, between 1500 and $2500 \mathrm{~m}$, and above $2500 \mathrm{~m}$ elevation, respectively. The negative MB values in table 3 demonstrate that all four SBP underestimated the observed precipitation at below $1500 \mathrm{~m}$ elevation. It is noteworthy that GSMaP-Gauge effectively reduces the systematic errors (30\% of RE) of GSMaP-MVK with bias-correction using the daily CPC gauge-based observation, which is only $2.6 \%$ when GPCC monthly gauge-analysis used in IMERG data set. The CC values in IMERG-UNCORR and GSMaP-MVK are 0.14 and 0.58 , respectively, which is 0.3 and 0.6 in IMERG-CORR and GSMaP-Gauge (Table 3). 
Table 3. Statistical metrics in low-elevation (below-1500 m), mid-elevation (between 1500 and $2500 \mathrm{~m}$ ), and high-elevation (above $2500 \mathrm{~m}$ ), as well as in the national scale. Values are calculated by averaging the precipitation values at each station.

\begin{tabular}{|c|c|c|c|c|c|c|}
\hline Regions & Datasets & $\begin{array}{c}\text { Mean } \\
(\mathrm{mm} / \\
\text { day })\end{array}$ & $\begin{array}{l}\text { MB }(\mathrm{mm} / \\
\text { day) }\end{array}$ & NRMSE & $\mathrm{CC}$ & RE (\%) \\
\hline \multirow{4}{*}{ Below $1500 \mathrm{~m}$} & IMERG-UNCORR & 4.33 & -0.54 & 0.55 & 0.14 & 11.01 \\
\hline & IMERG-CORR & 4.2 & -0.67 & 0.5 & 0.3 & 13.68 \\
\hline & GSMaP-MVK & 2.63 & -2.23 & 0.64 & 0.58 & 45.9 \\
\hline & GSMaP-Gauge & 4.1 & -0.77 & 0.43 & 0.6 & 15.79 \\
\hline \multirow{4}{*}{$\begin{array}{c}\text { Between } \\
\text { 1500-2500 m }\end{array}$} & IMERG-UNCORR & 3.1 & -2.35 & 0.69 & 0.29 & 43.13 \\
\hline & IMERG-CORR & 3.75 & -1.7 & 0.6 & 0.37 & 31.22 \\
\hline & GSMaP-MVK & 2.29 & -3.16 & 0.76 & 0.71 & 58.05 \\
\hline & GSMaP-Gauge & 3.96 & -1.49 & 0.48 & 0.72 & 27.3 \\
\hline \multirow{4}{*}{$\begin{array}{c}\text { Above } 2500 \\
\text { m }\end{array}$} & IMERG-UNCORR & 1.69 & -1.07 & 0.98 & 0.36 & 38.83 \\
\hline & IMERG-CORR & 2.22 & -0.55 & 0.82 & 0.69 & 19.79 \\
\hline & GSMaP-MVK & 1.6 & -1.16 & 0.97 & 0.51 & 42.06 \\
\hline & GSMaP-Gauge & 3.4 & 0.64 & 1.2 & -0.09 & 22.96 \\
\hline \multirow{4}{*}{$\begin{array}{l}\text { National } \\
\text { Scale }\end{array}$} & IMERG-UNCORR & 3.85 & -1.01 & 0.61 & 0.2 & 20.81 \\
\hline & IMERG-CORR & 3.96 & -0.91 & 0.54 & 0.37 & 18.69 \\
\hline & GSMaP-MVK & 2.48 & -2.39 & 0.69 & 0.59 & 49.06 \\
\hline & GSMaP-Gauge & 4.02 & -0.85 & 0.48 & 0.58 & 17.44 \\
\hline
\end{tabular}

The MB and NRMSE were higher in IMERG products, whereas CC was higher in GSMaP products except above $2500 \mathrm{~m}$. The result further indicates that in lowland with moderate precipitation, IMERG products are more consistent with estimating the precipitation amount (smaller $\mathrm{MB}$ ), while GSMaP products can better represent the spatial distribution (higher $\mathrm{CC}$ ) of observed precipitation. In a mid-elevation region characterized by high precipitation, GSMaP-Gauge performs reasonably well with lower MB (-1.49 mm/day), NRMSE (0.48), and higher CC (0.72) among all SBP. Meanwhile, CC-value is very similar between GSMaP-MVK and GSMaP-Gauge. In this region, IMERG products are less capable of representing the spatial pattern (lower CC-value) even after the GPCC gauge calibration. Systematic errors are significantly improved (reduced RE) after the gauge calibration in both IMERG-CORR and GSMaPGauge at mid and low-elevation areas.

Further, in high-elevation areas with complex terrain and low precipitation, gauge calibrated IMERG-CORR underestimated, and GSMaP-Gauge overestimated mean monthly precipitation with similar $\mathrm{MB}$ of -0.55 and $0.64 \mathrm{~mm} /$ day, respectively. Overall, at national scale, GSMaP-Gauge outperforms all SBPs indicating that GSMaPGauge shows better overall performance followed by IMERG-CORR, IMERG-UNCORR and GSMaP-MVK. 


\subsection{Precipitation detection capability}

To analyze the precipitation detection capability of four SBPs, POD, FAR and CSI is calculated at each station and presented in Figure 3. All SBP products under the study showed an overall good performance, with the IMERG-CORR showing the best performance with a POD higher than $70 \%$ at each station (Figure $3 \mathrm{~d}$ ), followed by GSMaP-Gauge (POD > 65\%) (Figure 3j). Both gauge calibrated products show good performance compared to the un-calibrated versions in detecting the observed precipitation events. In general, the SBPs products had the high capability to correctly estimate overall rain and no-rain events (CSI $<40 \%)$ (Figure 3c, f, i and 1). Among them, both un-calibrated datasets show similar CSI ( 40\%), where IMERG-CORR had better capability to detect rain and no-rain events (CSI <30\%) (Figure 3f). Further, IMERGCORR also showed the lowest FAR among all SBPs, indicating only about $40 \%$ of estimated precipitation at most of the stations when there is no rainfall from observed data (Figure 3e). Again, both un-corrected versions showed a similar capability to detect false precipitation events; however, the difference is small.

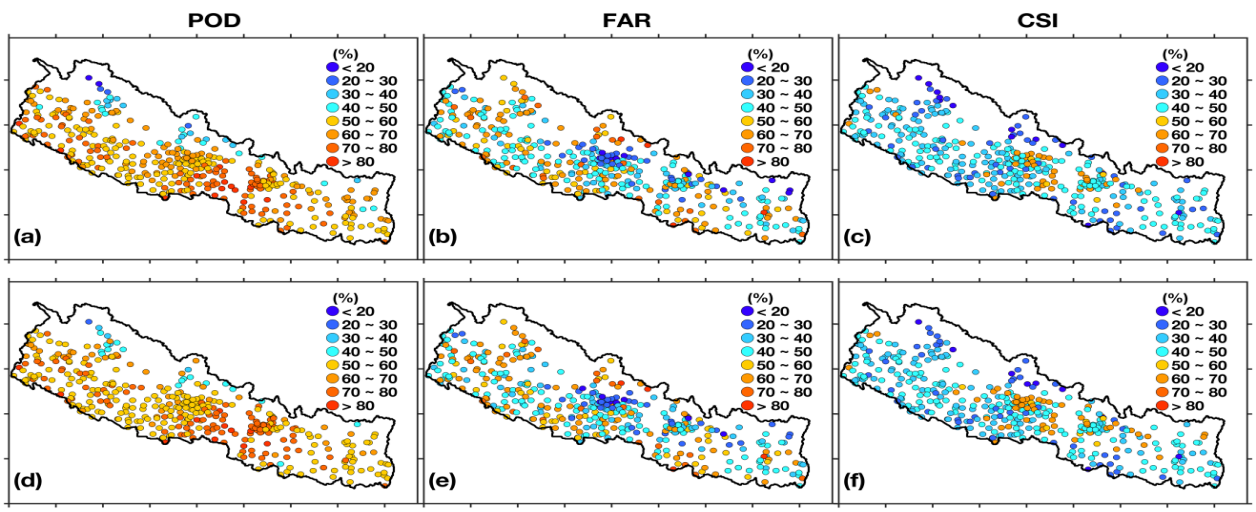

Figure 3. Precipitation detection capability of (a,d,g,h) POD, (b,e,j,k) FAR and (c,f,i,l) CSI for IMERG-UNCORR (first row: $a, b, c)$, IMERG-CORR (second row: d,e,f), GSMaPMVK (third row: g,h,i) and GSMaP-Gauge (forth row: j,k,l) during the study period. 


\section{Discussion}

SBP products are potential alternatives for estimating precipitation - where there is no representation of gauge data, which creates new opportunities for hydro-meteorological phenomena in understanding and applying remotely-sensed information. In this study, we presented spatial performance of four satellite-based precipitation datasets from the GPM-era SBP (GPM-IMERG and GSMaP) product with the gauge observations from Nepal. In all four SBP datasets, GSMaP-Gauge has the best overall performance, followed by IMERG-CORR, IMERG-UNCORR, and GSMaP-MVK. Several previous studies have also found that gauge-calibrated SBP generally show higher accuracy than their satellite-only versions due to observed gauge adjustment on these datasets (Sungmin et al., 2017; Wang et al., 2017; Yuan et al., 2019). However, precipitation estimates from IMERG-C and GSMaP-Gauge largely depend on the gauge-based GPCC and CPC data set, respectively. If the gauge-based data set represents precipitation estimates better in a region, then these gauge-calibrated SBP datasets will also show remarkable scores in this region. Thus, quality calibrated gauge datasets remarkably influence the accuracy of the IMERG-C, and GSMaP-Gauge precipitation estimates.

GPM-IMERG precipitation products are based on PMW and IR sensors available from Low Earth Orbital (LEO) and geostationary satellites. It also uses the datasets of surface temperature, relative humidity, and surface pressure provided by European Centre for Medium-Range Weather Forecasts (Huffman et al., 2017; Zhao et al., 2018). IMERG-UNCORR is satellite-only datasets where IMERG-CORRR was corrected using GPCC monthly precipitation-based coefficients. In comparison with satellite-only and gauge calibrated IMERG datasets, as expected, gauge calibrated IMERG-CORR systematically provides a more realistic precipitation estimate than its corresponding satellite-only (IMERG-UNCORR) data set (see Figure 2 and Table 3). IMERGCORR significantly improved the performance based on a monthly timescale as this precipitation estimate is strongly dependent on the GPCC gauge calibration. On the other hand, slightly improved performance on the daily time scale is more dependent on other components of the algorithms. Therefore, IMERG precipitation improvement at the daily timescale is a reflection of IMERG algorithms (Satge et al., 2018). Interestingly, both of the IMERG datasets had a weak correlation in low and mid-elevation areas as compared to the GSMaP product. Therefore, it can be assessed that the IMERG algorithm and error-correction method are more effective in balancing errors at highelevation areas or for low precipitation rates (Sharma et al., 2020a). This reveals that IMERG precipitation products are less reliable to detect higher precipitation rates.

Regarding GSMaP products, GSMaP-MVK largely underestimated the mean annual precipitation over the country, but, the negative bias was significantly reduced in GSMaP-Gauge, which was calibrated with CPC daily gauge data. Both of these datasets well captured the spatial pattern of precipitation over the country. Therefore, the algorithms used in GSMaP product are more proficient at capturing the spatial pattern of observed precipitation than those used in IMERG. Meanwhile, the relatively weaker performance of GSMaP-Gauge in high-elevation with lower precipitation rate might be related to quality of assembled gauge observation in CPC datasets. In general, the considerable underestimation for gauge-adjusted datasets may be attributed to 
the sparse, unevenly spaced gauge stations and the optimal interpolation technique. Another reason might be subjected to the fact that both PMW and IR satellites have difficulty detecting shallow orographic precipitation (Derin et al., 2016; Satge et al., 2018; Ushio et al., 2009). Thus, it seems important to calibrate satellite-based precipitation estimates at different rain rates and higher elevations.

However, SBP are indirect measurements that are based on satellite/sensor constellations, including PMW and IR sensors onboard LEO and geosynchronous satellites, and are subjected to uncertainty due to technical limitations (Sharma et al., 2020a; Sharma et al., 2020d). Indeed, the irregular sampling and limited overpass of LEO PMW measurements impede the correct capture of short-term, and slight precipitation events. We also found that the complex terrain and strong local convectional weather significantly influence the satellite rainfall retrieval and result in unexpected errors between satellite estimates and gauge observations.

\section{Conclusion}

This study attempts to evaluate the spatial pattern of precipitation in version 5 IMERG and version 6 GSMaP products, including satellite-only (IMERG-UNCORR and GSMaP-MVK) and gauge calibrated (IMERG-CORR and GSMaP-Gauge) products, against 387-gauge measurements in Nepal from April 2014 to December 2016. Conventional statistical metrics and evaluation scores were used to quantify the performances of these SBPs.

The precipitation amount in SBPs differs significantly, depending on the location. All four SBP datasets underestimated the observed precipitation over Nepal. However, all four datasets can capture the main spatial precipitation pattern (highest precipitation concentrated over mid-elevation areas of the central region). The precipitation estimated from both gauge calibrated SBP (IMERG-CORR and GSMaP-Gauge) data -sets were better than that estimated from satellite-only (IMERG-UNCORR and GSMaP-MVK) datasets. In low and mid-elevation areas (below $2500 \mathrm{~m}$ ) with relatively high precipitation, GSMaP-Gauge performs best in estimating precipitation amount and reflecting the observed spatial patterns among the four datasets. However, in highelevation areas (above $2500 \mathrm{~m}$ ) with complex topography, IMERG-CORR shows smaller $\mathrm{MB}$ and RRMSE values and higher $\mathrm{R}$ values than GSMaP-Gauge, IMERG-UNCORR, and GSMaP-MVK.

During the study period, when we choose $1 \mathrm{~mm} /$ day as the threshold of the daily rainfall event, IMERG product shows a better ability to detect actual precipitation (higher POD) than GSMaP product. IMERG-CORR shows the best performance for detecting no-precipitation events (lowest FAR scores) among the selected datasets. However, all four SBPs accurately detect (CSI $<40 \%$ ) precipitation and no-precipitation events across the country.

The present work fills the gap of the lack of a systematic evaluation for the four GPM-Era SBPs in Nepal. This comprehensive evaluation delivers a statistical basis and provides a concrete outlook on data selection in meteorological, hydrological, glaciological, and disaster-related studies within the study region. 
Acknowledgments: The authors express their sincere thanks to the scientists at the NASA and JAXA, who were responsible for the development of the IMERG and GSMaP algorithms and for providing satellite precipitation data. The DHM and the government of Nepal are also acknowledged for providing the observed precipitation datasets. The authors express their gratitude to Mr. Shankar Sharma for providing valuable suggestions and help for the study.

Conflicts of Interest: The authors declare no conflict of interest.

\section{References}

Aryal, D., Wang, L., Adhikari, T. R., Zhou, J., Li, X., Shrestha, M., Wang, Y. and Chen, D. (2020) A Model-Based Flood Hazard Mapping on the Southern Slope of Himalaya. Water, 12: 540. https://doi.org/10.3390/w12020540

Bhatt, B. C. and Nakamura, K. (2005) Characteristics of monsoon rainfall around the Himalayas revealed by TRMM precipitation radar. Monthly Weather Review, 133: 149-165. https:// doi.org/ 10.1175/Mwr-2846.1

Bookhagen, B. and Burbank, D. W. (2006) Topography, relief, and TRMM-derived rainfall variations along the Himalaya. Geophysical Research Letters, 33. Artn L08405. https://doi. org/10.1029/2006gl026037.

Brown, J. E. (2006) An analysis of the performance of hybrid infrared and microwave satellite precipitation algorithms over India and adjacent regions. Remote Sensing of Environment, 101: 63-81.

Chen, F. R. and Li, X. (2016) Evaluation of IMERG and TRMM 3B43 Monthly Precipitation Products over Mainland China. Remote Sensing, 8.

Chen, Y., Sharma, S., Zhou, X., Yang, K., Li, X., Niu, X., Hu, X. and Khadka, N. (2021) Spatial performance of multiple reanalysis precipitation datasets on the southern slope of central Himalaya. Atmospheric Research, 250: 105365. https://doi.org/10.1016/j. atmosres.2020.105365

Daly, C., Slater, M. E., Roberti, J. A., Laseter, S. H. and Swift, L. W. (2017) High-resolution precipitation mapping in a mountainous watershed: ground truth for evaluating uncertainty in a national precipitation dataset. International Journal of Climatology, 37: 124-137. https://doi.org/10.1002/joc.4986

Dawadi, B., Saroj, R. H. A. D. L., Ishwar, P. and Shrestha, K. (2020) A Short Note on Linkage of Climatic Records between Terai and Mid-mountain of Central Nepal. Journal of Geographical Research| Volume, 3.

Derin, Y., Anagnostou, E., Berne, A., Borga, M., Boudevillain, B., Buytaert, W., Chang, C. H., Delrieu, G., Hong, Y., Hsu, Y. C., Lavado-Casimiro, W., Manz, B., Moges, S., Nikolopoulos, E. I., Sahlu, D., Salerno, F., Rodriguez-Sanchez, J. P., Vergara, H. J. and Yilmaz, K. K. (2016) Multiregional Satellite Precipitation Products Evaluation over Complex Terrain. Journal of Hydrometeorology, 17: 1817-1836.

Diodato, N., Tartari, G. and Bellocchi, G. (2010) Geospatial Rainfall Modelling at Eastern Nepalese Highland from Ground Environmental Data. Water Resources Management, 24: 2703-2720. https://doi.org/10.1007/s11269-009-9575-2

Duncan, J. M. and Biggs, E. M. (2012) Assessing the accuracy and applied use of satellite-derived precipitation estimates over Nepal. Applied Geography, 34: 626-638.

Hamal, K., Khadka, N., Rai, S., Joshi, B. B., Dotel, J., Khadka, L., Bag, N., Ghimire, S. K. and Shrestha, D. (2020a) Evaluation of the TRMM Product for Spatio-temporal Characteristics 
of Precipitation over Nepal (1998-2018). Journal of Institute of Science and Technology, 25: 39-48.

Hamal, K., Sharma, S., Baniya, B., Khadka, N. and Zhou, X. (2020b) Inter-Annual Variability of Winter Precipitation Over Nepal Coupled With Ocean-Atmospheric Patterns During 1987-2015. Frontiers in Earth Science, 8: 161. https://doi.org/10.3389/feart.2020.00161

Hamal, K., Sharma, S., Khadka, N., Baniya, B., Ali, M., Shrestha, M. S., Xu, T., Shrestha, D. and Dawadi, B. (2020c) Evaluation of MERRA-2 Precipitation Products Using Gauge Observation in Nepal. Hydrology, 7: 40. https://doi.org/10.3390/hydrology7030040

Hamal, K., Sharma, S., Pokharel, B., Shrestha, D., Talchabhadel, R., Shrestha, A. and Khadka, N. (2021) Changing pattern of drought in Nepal and associated atmospheric circulation. Atmospheric Research: 105798.

Hannah, D. M., Kansakar, S. R., Gerrard, A. J. and Rees, G. (2005) Flow regimes of Himalayan rivers of Nepal: nature and spatial patterns. Journal of Hydrology, 308: 18-32. 10.1016/j. jhydrol.2004.10.018

Hou, A. Y., Kakar, R. K., Neeck, S., Azarbarzin, A. A., Kummerow, C. D., Kojima, M., Oki, R., Nakamura, K. and Iguchi, T. (2014) The Global Precipitation Measurement Mission. Bulletin of the American meteorological Society, 95: 701-+. 10.1175/Bams-D-13-00164.1

Huffman, G. J., Adler, R. F., Bolvin, D. T. and Nelkin, E. J. 2010. The TRMM Multi-Satellite Precipitation Analysis (TMPA). In Satellite Rainfall Applications for Surface Hydrology, Gebremichael, M. and Hossain, F. (eds.). Springer Netherlands: Dordrecht; 3-22.

Huffman, G. J., Bolvin, D. T., Braithwaite, D., Hsu, K., Joyce, R., Xie, P. and Yoo, S.-H. (2015a) NASA global precipitation measurement (GPM) integrated multi-satellite retrievals for GPM (IMERG). Algorithm Theoretical Basis Document (ATBD) Version, 4: 26.

Huffman, G. J., Bolvin, D. T., Braithwaite, D., Hsu, K., Joyce, R., Xie, P. and Yoo, S.-H. (2019) NASA global precipitation measurement (GPM) integrated multi-satellite retrievals for GPM (IMERG). Algorithm Theoretical Basis Document (ATBD) Version 06, 6: 26.

Huffman, G. J., Bolvin, D. T. and Nelkin, E. J. (2015b) Integrated Multi-satellitE Retrievals for GPM (IMERG) technical documentation. NASA/GSFC Code, 612: 47.

Huffman, G. J., Bolvin, D. T. and Nelkin, E. J. (2017) Integrated Multi-satellitE Retrievals for GPM (IMERG) technical documentation. NASA/GSFC Code, 612: 47.

Immerzeel, W. W., Lutz, A., Andrade, M., Bahl, A., Biemans, H., Bolch, T., Hyde, S., Brumby, S., Davies, B. and Elmore, A. (2020) Importance and vulnerability of the world's water towers. Nature, 577: 364-369.

Islam, M., Das, S. and Uyeda, H. (2010) Calibration of TRMM derived rainfall over Nepal during 1998-2007. The Open Atmospheric Science Journal, 4.

Kidd, C. and Huffman, G. (2011) Global precipitation measurement. Meteorological Applications, 18: 334-353.

Krakauer, N. Y., Pradhanag, S. M., Lakhankar, T. and Jha, A. K. (2013) Evaluating Satellite Products for Precipitation Estimation in Mountain Regions: A Case Study for Nepal. Remote Sensing, 5: 4107-4123. https://doi.org/10.3390/rs5084107

Nayava, J. L. (1980) Rainfall in Nepal. Himalayan Review, 12: 1-18.

Nepal, B., Shrestha, D., Sharma, S., Shrestha, M. S., Aryal, D. and Shrestha, N. (2021) Assessment of GPM-Era Satellite Products'(IMERG and GSMaP) Ability to Detect Precipitation Extremes over Mountainous Country Nepal. Atmosphere, 12: 254.

Pokharel, B., Wang, S. Y. S., Meyer, J., Marahatta, S., Nepal, B., Chikamoto, Y. and Gillies, R. (2019) The east-west division of changing precipitation in Nepal. International Journal of Climatology, 40: 3348-3359. https://doi.org/10.1002/joc.6401 
Prakash, S., Mitra, A. K., AghaKouchak, A., Liu, Z., Norouzi, H. and Pai, D. S. (2018) A preliminary assessment of GPM-based multi-satellite precipitation estimates over a monsoon dominated region. Journal of Hydrology, 556: 865-876.

Satge, F., Hussain, Y., Bonnet, M. P., Hussain, B. M., Martinez-Carvajal, H., Akhter, G. and Uagoda, R. (2018) Benefits of the Successive GPM Based Satellite Precipitation Estimates IMERGV03,-V04,-V05 and GSMaP-V06,-V07 Over Diverse Geomorphic and Meteorological Regions of Pakistan. Remote Sensing, 10.

Satge, F., Xavier, A., Zola, R. P., Hussain, Y., Timouk, F., Garnier, J. and Bonnet, M. P. (2017) Comparative Assessments of the Latest GPM Mission's Spatially Enhanced Satellite Rainfall Products over the Main Bolivian Watersheds. Remote Sensing, 9. UNSP 369, https://doi.org/10.3390/rs9040369

Schneider, U., Ziese, M., Meyer-Christoffer, A., Finger, P., Rustemeier, E. and Becker, A. (2016) The new portfolio of global precipitation data products of the Global Precipitation Climatology Centre suitable to assess and quantify the global water cycle and resources. Water Resources Assessment and Seasonal Prediction, 374: 29-34. 10.5194/piahs-374-29-2016

Seto, S., Iguchi, T. and Oki, T. (2013) The Basic Performance of a Precipitation Retrieval Algorithm for the Global Precipitation Measurement Mission's Single/Dual-Frequency Radar Measurements. Ieee Transactions on Geoscience and Remote Sensing, 51: 5239-5251.

Sharma, S., Bajracharya, R. M., Sitaula, B. K. and Merz, J. (2005) Water quality in the Central Himalaya. Current Science, 89: 774-786.

Sharma, S., Chen, Y., Zhou, X., Yang, K., Li, X., Niu, X., Hu, X. and Khadka, N. (2020a) Evaluation of GPM-Era Satellite Precipitation Products on the Southern Slopes of the Central Himalayas Against Rain Gauge Data. Remote Sensing, 12: 1836. https://doi.org/10.3390/ rs12111836

Sharma, S., Hamal, K., Khadka, N., Ali, M., Subedi, M., Hussain, G., Ehsan, M. A., Saeed, S. and Dawadi, B. (2021a) Projected Drought Conditions over Southern Slope of the Central Himalaya Using CMIP6 Models. Earth Systems and Environment: 1-11. https://doi. org/10.1007/41748-021-00254-1

Sharma, S., Hamal, K., Khadka, N. and Joshi, B. B. (2020b) Dominant pattern of year-to-year variability of summer precipitation in Nepal during 1987-2015. Theoretical and applied climatology, 142: 1071-1084. https://doi.org/10.1007/s00704-020-03359-1

Sharma, S., Khadka, N., Hamal, K., Baniya, B., Luintel, N. and Joshi, B. B. (2020c) Spatial and Temporal Analysis of Precipitation and Its Extremities in Seven Provinces of Nepal (2001-2016). Applied Ecology and Environmental Sciences, 8: 64-73. https://doi.org/10.12691/ aees-8-2-4

Sharma, S., Khadka, N., Hamal, K., Shrestha, D., Talchabhadel, R. and Chen, Y. (2020d) How Accurately Can Satellite Products (TMPA and IMERG) Detect Precipitation Patterns, Extremities, and Drought Across the Nepalese Himalaya? Earth and Space Science, 7: e2020EA001315. https://doi.org/10.1029/2020ea001315

Sharma, S., Khadka, N., Nepal, B., Ghimire, S. K., Luintel, N. and Hamal, K. (2021b) Elevation Dependency of Precipitation over Southern Slope of Central Himalaya. Jalawaayu, 1: $1-14$.

Shen, Y. and Xiong, A. Y. (2016) Validation and comparison of a new gauge-based precipitation analysis over mainland China. International Journal of Climatology, 36: 252-265. 10.1002/ joc.4341

Shige, S., Yamamoto, T., Tsukiyama, T., Kida, S., Ashiwake, H., Kubota, T., Seto, S., Aonashi, K. and Okamoto, K. (2009) The GSMaP Precipitation Retrieval Algorithm for Microwave Sounders-Part I: Over-Ocean Algorithm. Ieee Transactions on Geoscience and Remote Sensing, 47: 3084-3097. 
Shrestha, D. and Deshar, R. (2014) Spatial Variations in the diurnal pattern of precipitation over Nepal Himalayas. Nepal Journal of Science and Technology, 15: 57-64.

Shrestha, D., Sharma, S., Hamal, K., Jadoon, U. K. and Dawadi, B. (2021) Spatial Distribution of Extreme Precipitation Events and Its Trend in Nepal. Environmental Sciences, 9: 58-66.

Shrestha, M. L. (2000) Interannual variation of summer monsoon rainfall over Nepal and its relation to Southern Oscillation Index. Meteorology and Atmospheric Physics, 75: 21-28. 10.1007/s007030070012

Sun, Q. H., Miao, C. Y., Duan, Q. Y., Ashouri, H., Sorooshian, S. and Hsu, K. L. (2018) A Review of Global Precipitation Data Sets: Data Sources, Estimation, and Intercomparisons. Reviews of Geophysics, 56: 79-107.

Sungmin, O., Foelsche, U., Kirchengast, G., Fuchsberger, J., Tan, J. and Petersen, W. A. (2017) Evaluation of GPM IMERG Early, Late, and Final rainfall estimates using WegenerNet gauge data in southeastern Austria. Hydrology and Earth System Sciences, 21: 6559-6572.

Talchabhadel, R. and Karki, R. (2019) Assessing climate boundary shifting under climate change scenarios across Nepal. Environmental Monitoring and Assessment, 191: 520. https://doi. org/10.1007/10661-019-7907-0.

Talchabhadel, R., Karki, R., Thapa, B. R., Maharjan, M. and Parajuli, B. (2018) Spatio-temporal variability of extreme precipitation in Nepal. International Journal of Climatology, 38: 42964313. https://doi.org/10.1002/joc.5669

Tan, J., Petersen, W. A., Kirstetter, P. E. and Tian, Y. D. (2017) Performance of IMERG as a Function of Spatiotemporal Scale. Journal of Hydrometeorology, 18: 307-319. 10.1175/Jhm-D-16-0174.1

Tang, G. Q., Ma, Y. Z., Long, D., Zhong, L. Z. and Hong, Y. (2016) Evaluation of GPM Day-1 IMERG and TMPA Version-7 legacy products over Mainland China at multiple spatiotemporal scales. Journal of Hydrology, 533: 152-167.

Tian, Y.D. andPeters-Lidard,C.D.(2010)Aglobalmapofuncertaintiesinsatellite-based precipitation measurements. Geophysical Research Letters, 37. Artn L2440710.1029/2010g1046008

Ushio, T., Sasashige, K., Kubota, T., Shige, S., Okamoto, K., Aonashi, K., Inoue, T., Takahashi, N., Iguchi, T., Kachi, M., Oki, R., Morimoto, T. and Kawasaki, Z. I. (2009) A Kalman Filter Approach to the Global Satellite Mapping of Precipitation (GSMaP) from Combined Passive Microwave and Infrared Radiometric Data. Journal of the Meteorological Society of Japan, 87a: 137-151.

Viviroli, D., Archer, D. R., Buytaert, W., Fowler, H. J., Greenwood, G. B., Hamlet, A. F., Huang, Y., Koboltschnig, G., Litaor, M. I., Lopez-Moreno, J. I., Lorentz, S., Schadler, B., Schreier, H., Schwaiger, K., Vuille, M. and Woods, R. (2011) Climate change and mountain water resources: overview and recommendations for research, management and policy. Hydrology and Earth System Sciences, 15: 471-504. 10.5194/hess-15-471-2011

Viviroli, D., Durr, H. H., Messerli, B., Meybeck, M. and Weingartner, R. (2007) Mountains of the world, water towers for humanity: Typology, mapping, and global significance. Water Resources Research, 43. Artn W0744710.1029/2006wr005653

Viviroli, D. and Weingartner, R. (2004) The hydrological significance of mountains: from regional to global scale. Hydrology and Earth System Sciences, 8: 1016-1029.

Wang, Z. L., Zhong, R. D., Lai, C. G. and Chen, J. C. (2017) Evaluation of the GPM IMERG satellitebased precipitation products and the hydrological utility. Atmospheric Research, 196: 151163.

Yamamoto, M. K., Ueno, K. and Nakamura, K. (2011) Comparison of Satellite Precipitation Products with Rain Gauge Data for the Khumb Region, Nepal Himalayas. Journal of the Meteorological Society of Japan, 89: 597-610. 10.2151/jmsj.2011-601 
Yatagai, A. and Kawamoto, H. (2008) Quantitative estimation of orographic precipitation over the Himalayas by using TRMM/PR and a dense network of rain gauges. Remote Sensing and Modeling of the Atmosphere, Oceans, and Interactions Ii, 7148. Artn 71480c

$10.1117 / 12.811943$

Yuan, F., Zhang, L. M., Soe, K. M. W., Ren, L. L., Zhao, C. X., Zhu, Y. H., Jiang, S. H. and Liu, Y. (2019) Applications of TRMM- and GPM-Era Multiple-Satellite Precipitation Products for Flood Simulations at Sub-Daily Scales in a Sparsely Gauged Watershed in Myanmar. Remote Sensing, 11.

Zhao, H. G., Yang, B. G., Yang, S. T., Huang, Y. C., Dong, G. T., Bai, J. and Wang, Z. W. (2018) Systematical estimation of GPM-based global satellite mapping of precipitation products over China. Atmospheric Research, 201: 206-217. 